\title{
PELATIHAN KETERAMPILAN MEMBUAT SLIDE PERSENTASI EFEKTIF DENGAN EFEK GRADASI PADA MAHASISWA FAKULTAS ILMU BUDAYA UNILAK
}

\author{
Loneli Costaner*1, Guntoro ${ }^{2}$, Lisnawita ${ }^{3}$ \\ ${ }^{1,2,3}$ Teknik Informatika, Fakultas Ilmu Komputer, Universitas Lancang Kuning \\ *E-mail: lonelicostaner@unilak.ac.id
}

\begin{abstract}
Teaching and learning process is an integral in the achievement of human resources who have the skills in the field in accordance with the goals of a college. Students who undergo the study other than he get the knowledge in the field that he studied, will also be given the learning experience given the task by the lecturer supervisor of the course and then the results are feasible for the percentage of campus forums with tools and complete electronic media. Nowadays, the percentage becomes the obstacle by students to get the perfect score, because the percentage is related to the presentation slide which is interesting and easy to understand by the audience. The percentage slide also becomes an assessment at the moment of presentation in front of the class forum, the student is not yet understand how to make an interesting and effective presentation so that the idea is well conveyed. In addition, students also difficult to make a presentation with a combination of images and writing because it has not got the skills to design the slide so much the results of the presentation of what is with a fairly satisfactory percentage value. In today's digital age, it can be said that any profession of someone in the world of organization, both business world and academic world can not be separated from the necessity to do the exposure to explain the purpose of a problem or information. Ability to present good information with an attractive means is necessary to get the ideas and ideas to the person who received the information. Good presentation skills, interesting and informative is needed everyone so that ideas or ideas can be easily understood. One of the media presentations to make the ideas submitted so more informative and interesting is to use Ms. Power point.
\end{abstract}

Keywords-Percentage, Ms. Power point

\begin{abstract}
Abstrak
Proses belajar mengajar adalah suatu yang tak terpisahkan dalam tercapainya sumber daya manusia yang mempunyai skill dibidangnya sesuai dengan tujuan sebuah perguruan tinggi. Mahasiswa yang menjalani studi selain ia mendapatkan ilmu pengetahuan di bidang yang ia dalami, juga akan diberikan pengalaman belajar dengan diberikan tugas oleh dosen pembimbing matakuliah tersebut dan kemudian hasil nya layak untuk di persentasikan di forum kampus dengan alat dan media elektronik yang lengkap. Saat ini persentasi jadi hambatan oleh mahasiswa untuk mendapatkan nilai yang sempurna, karena persentasi berkaitan dengan slide persentasi yang menarik dan mudah dipahami oleh audien. Slide persentasi juga menjadi penilaian pada saat persentasi didepan forum kelas, kedala mahasiswa adalah belum memahami bagaimana membuat persentasi yang menarik dan efektif sehingga tersampaikannya gagasan dengan baik. Selain itu juga mahasiswa kesulitan membuat persentasi dengan kombinasi gambar dan tulisan karena belum memili skill untuk merancang slide sehingga banyak hasil persentasi apa adanya dengan nilai persentasi yang cukup memuaskan. Di zaman digital saat ini, bisa dikatakan apapun profesi sesorang dalam dunia oraganisasi, baik dunia bisnis maupun dunia akademis tidak terlepas dari keharusan untuk melakukan pemaparan guna menjelaskan maksud dari suatu masalah atau pun informasi. Kemampuan memaparkan informasi yang baik dengan sarana yang menarik sangat diperlukan untuk tersampainya ide dan gagasan kepada orang yang menerima informasi tersebut. Keterampilan presentasi yang baik, menarik dan informatif sangat diperlukan semua orang agar ide atau gagasan yang disampaikan bisa mudah dipahami. Salah satu media persentasi untuk membuat
\end{abstract}


DINAMISIA - Jurnal Pengabdian Kepada Masyarakat Vol. 2, No. 2 Desember 2018, Hal. 322-327

gagasan yang disampaikan jadi lebih informatif dan menarik adalah dengan menggunakan Ms. Power Point.

Kata Kunci: Persentasi, Ms. Power Point

\section{PENDAHULUAN}

Dunia akademik bisa dikatakan sebagai sarana untuk mencetak manusia menjadi seorang yang memiliki daya intlektual dibidangnya, sehingga ia menjadi suatu objek yang sangat diperhatikan dalam menghasilkan output yang berkwalitas.

Proses belajar mengajar adalah suatu yang tak terpisahkan dalam tercapainya sumber daya manusia yang mempunyai skill dibidangnya sesuai dengan tujuan sebuah perguruan tinggi. Mahasiswa yang menjalani studi selain ia mendapatkan ilmu pengetahuan di bidang yang ia tekuni, juga akan diberikan pengalaman belajar dengan diberikan tugas oleh dosen pengampu matakuliah tersebut dan kemudian hasil nya layak untuk dipersentasikan diforum kampus dengan alat dan media elektronik yang lengkap.

Diera digital saat ini, bisa dikatakan apapun profesi sesorang dalam dunia oraganisasi, baik dunia bisnis maupun dunia akademis tidak terlepas dari keharusan untuk melakukan pemaparan guna menjelaskan maksud dari suatu masalah atau pun informasi. Kemampuan memaparkan informasi yang baik dengan sarana yang menarik sangat diperlukan untuk tersampainya ide dan gagasan kepada orang yang menerima informasi tersebut. Keterampilan presentasi yang baik, menarik dan informatif sangat diperlukan semua orang agar ide atau gagasan yang disampaikan bisa mudah dipahami. Salah satu media persentasi untuk membuat gagasan yang disampaikan jadi lebih informatif dan menarik adalah dengan menggunakan Ms. Power Point.

MS. Power Point sebuah software aplikasi ciptaan Microsof ini dapat digunakan untuk membuat persentasi jadi lebih baik untuk menyampaikan ide maupun gagasan yang manarik, tentunya juga ditambahkan dengan sedikit polesan skiil pembuatnya. Dalam implementasi MS. Power Point dapat membuat dan menampilkan isi dalam bentuk slide slide, membantu mengorganisir informasi presentasi dan membantu dengan tampilan keseluruhan, menjalankan Wizard dalam mengorganisir informasi dan untuk merancang tampilan / presentasi, dengan animasi, text, suara maupu video, dengan fasilitas ini tentunya suasana persentasi jadi lebih hidup.

Dalam kaitannya dengan penggunaan Power Point, peran slide show sangat menentukan kesuksesan sebuah presentasi. Perlu diingat bahwa presentasi berupa slide show bisa berdiri sendiri seperti halnya suatu pameran ataupun iklan meski tanpa kehadiran seorang presenter sekalipun. Oleh karena itu, daya tarik materi dan teknik penyajian slide show menjadi hal yang sangat krusial (Munawar, 2016).

Saat ini sistem pembelajaran di beberapa Program Studi Fakultas Ilmu Budaya berjalan dengan baik, namun yang menjadi kendala dalam proses pengajaran tersebut adalah ketika mahasiswa diberi tugas oleh dosen pengampu kemudian untuk dipersentasikan setelah laporan tugas selesai, yaitu slide persentasi dipenuhi dengan paragraph. Fakta yang terjadi adalah mahasiswa menyalin apa yang ada dilaporan kedalam power point sehingga fungsi dari suatu aplikasi tersebut tidak pada tempatnya (Paragraf Persentasi) bukan lagi slide persentasi. Kondisi persentasi seperti hal tersebut membuat suasana kelas tidak nyaman dan audien dikelas tidak focus, mata melihat jadi risih, informasi yang dipaparkan akhirnya tidak tersampai dengan baik kepada audient.

\section{Permasalahan Mitra}

Permasalahan khusus yang dihadapi oleh mitra Mahasiswa Fakultas Ilmu Budaya adalah perlunya peningkatan SDM terhadap keterampilan dalam memaparkan ide maupun gagasan menggunakan slide power point yang efektif guna tersampaikan informasi tersebut kepada audien. Pemikiran ini berangkat dari tuntutan zaman digital yang mempengaruhi peluang prestasi dan dunia kerja. Dari hasil pengamatan dan diskusi kepada salah satu pimpinan yang ada dilingkungan Fakultas Ilmu Budaya dapat dipapar sebagai berikut.

1. Dalam mendukung kegiatan pengajaran mahasiswa masih menggunakan cara pemaparan persentasi apa adanya, dengan copy text kedalam slide power point. Tidak adanya teknik yang 
digunakan sehingga dirasa paparan persentasi tidak maksimal sehingga kurangnya minat belajar mahasiswa untuk mendalami makalah yang disusun oleh mahasiswa tersebut.

2. Dalam mengerjakan tugas matakuliah yang diampu terkait dengan presentasi juga masih sekedar mengerjakan tugas. Mahasiswa masih kesulitan dalam membuat persentasi makalah maupun untuk persentasi proposal hingga skripsi, karena belum memiliki keterampilan dsain persentasi.

Dengan permasalahan tersebut kami mengajukan IbM guna menyelesaikan kendala yang dihadapi mahasiswa dengan pelatihan membuat persentasi yang baik dengan sebuah aplikasi Ms. Power Point.

\section{METODE}

\subsection{Khalayak Sasaran}

Sasaran kegiatan ini adalah para Mahasiswa Prodi Bahasa Indonesia dan Prodi Sastra Daerah Fakultas Ilmu Budaya. Pemilihan dan penetapan sasaran pelatihan ini adalah mempertimbangkan terhadap permasalahan yang dihadapi oleh para mahasiswa tentang pembuatan dsain power point yang informatif. Dengan adanya pelatihan ini diharapkan mahasiswa Fakultas Ilmu Budaya memiliki keterampilan membuat dsain power point yang baik dan efektif dengan salah teknik effek pada MS.Power Point.

\subsection{Metode Kegiatan}

Metode kegiatan yang dilakukan pada pelatihan slide persentasi dilakukan lebih kurang 4 jam, akan dilaksanakan di labor Komputer Fasilkom UNILAK, adapun urutan kegiatan pelaksanaan pelatihan adalah sebagai berikut:

1. Pretest yaitu pelatihan akan diawali dengan penilaian kemampuan peserta pelatihan sebelum memulai pelatihan, penilaian dengan Prosedur pre test adalah suatu bentuk pertanyaan, yang akan ditanyakan kepada mahasiswa sebelum memulai pelatihan. Pertanyaan yang ditanya adalah materi yang akan diterapkan dalam pelatihan pada hari itu (materi baru). Pertanyaan itu biasanya dilakukan guru di awal pembukaan pelajaran.

2. Ceramah yaitu Metode ceramah digunakan untuk menjelaskan dasar-dasar teori terkait dengan pelatihan membuat persentasi menggunakan Ms. Power Point. Selain itu, metode ini juga memberikan pengetahuan serta pemahaman tentang manfaat dari Slide power Point yang informatif.

3. Simulasi Teknik dan Tool Gradasi yaitu Metode ini para peserta akan dipaparkan dan ditunjukkan bagaimana peran tool - tool dari Teknik Gradasi yang ada pada MS. Power point dapat menyulap slide persentasi jadi lebih informatif dan menarik. Peserta juga selain melihat bagaimana pemateri mensimulasikan teknik teknik gradasi, juga akan diulang menggunakan video tutorial.

4. Praktik yaitu Pada metode ini para peserta mempraktikkan semua materi yang sudah diberikan sebelumnya. Praktek dilakukan dengan setiap peserta menggunakan komputer dan juga dibekali dengan modul latihan. Metode ini digunakan untuk mengetahui bagaimana keterampilan atau skill peserta dalam mengaktualisasikan pemahaman dari arahan yang diberikan, karena setiap peserta akan berbeda dalam mendesain tampilan sebuah slide persentasi.

5. Post Test yaitu Metode ini dilakukan setelah seluruh materi disampaikan kepada peserta dimana fungsinya adalah untuk mengevaluasi sejauh mana peserta mendapatkan manfaat dari pelatihan, dimana penilaian dengan Prosedur post test adalah bentuk pertanyaan yang diberikan setelah pelajaran/materi telah disampaikan. Dengan kata lain, post test adalah evaluasi akhir saat materi yang di terapkan pada saat pelatihan diberikan yang mana seorang memberikan post test dengan maksud apakah mahasiswa sudah mengerti dan memahami mengenai materi yang telah dipraktekkan. 


\section{Langkah Kegiatan}

Beberapa langkah kegiatan yang dilakukan untuk melaksanakan program pengabdian kepada masyarakat yaitu:

1. Melakukan koordinasi kepada mitra

2. Mengobservasi sejauh mana mahasiswa mitra dalam memaparkan ide, gagasan dari suatu tugas maupun proposal diorganisasi mitra

3. Mengajukan ijin pengabdian kepada mitra untuk melaksanakan pelatihan

4. Memberikan undangan kepada mahasiswa yang akan menjadi peserta pelatihan

5. Melaksanakan pelatihan

6. Membuat laporan hasil kegiatan

\section{HASIL DAN PEMBAHASAN}

\section{Langkah Kegiatan:}

1. Bahwa kegiatan pelaksana pengabdian masyarakat dengan judul Pelatihan Keterampilan Membuat Slide Persentasi efektif Dilaksanakan pada hari Senin 16 April 2018 dilabor komputer FASILKOM.

2. Acara dilaksanakan diawali dengan pembukaan oleh tim pengabdian

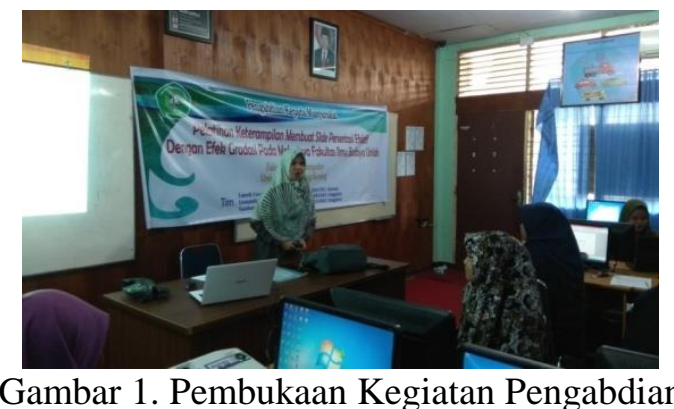

3. Sebelum praktek dimulai akan dilakukan Pre-test terlebih dahulu dengan mengisi form pemahaman tentang pembuatan slide persentasi yang efektif, dengan 9 pertanyaan kemudian mengumpulkan slide persentasi yang pernah dibuat oleh mahasiswa.

4. Sebelumnya Peserta diwajibkan membawa 1 buah tugas/makalah softcopy dimana peserta akan di test membuat slide persentasi tanpa teknik apapun sesuai pemahaman peserta sebelumnya menggunakan komputer yang telah disiapkan.

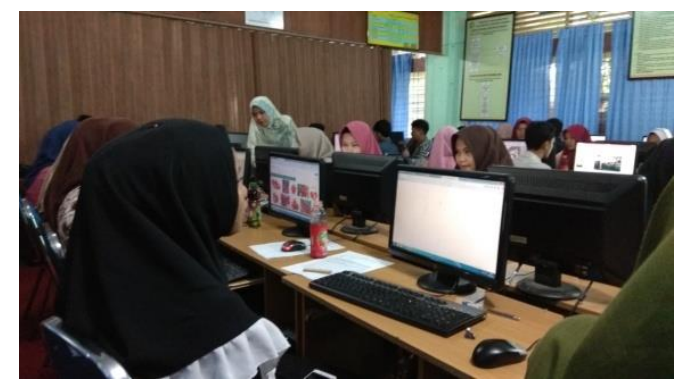

Gambar 2. Peserta Membuat Slide

5. Selanjutnya pemateri akan memaparkan tentang pemahaman suatu fungsi, Manfaat serta kesalahan kesalahan yang sering terjadi dalam merancang slide persentasi, menggunakan laptop dan ditampilkan kelayar Infocus. 


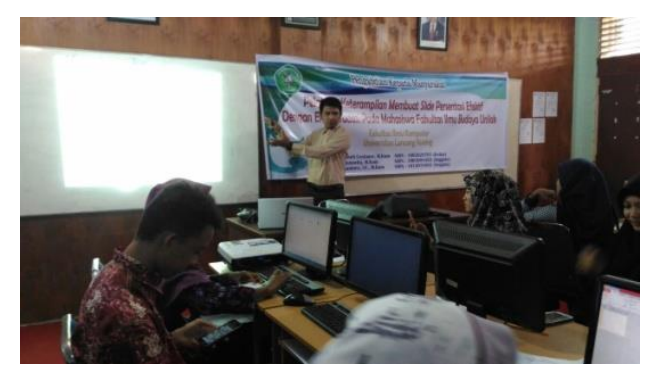

Gambar 3. Penyampaian Materi Presentasi

6. Kemudian pemateri akan mensimulasikan Teknik Gradasi, contoh contoh teknik gradasi serta bagaimana menerapkan teknik gradasi.

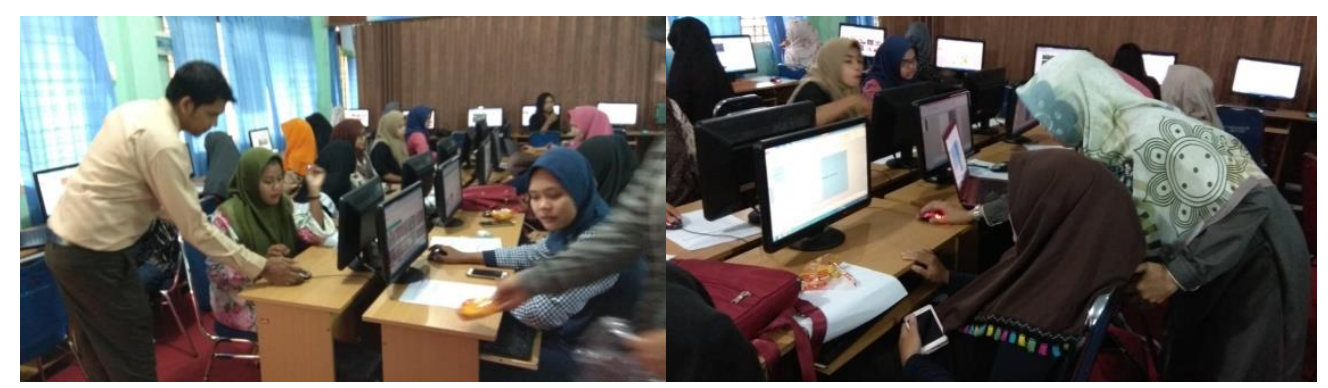

Gambar 4. Simulasi Teknik Gradasi

7. Quisioner Posttest akan diberikan kepada peserta setelah pengujian pemaparan slide yang telah dirancang oleh peserta dengan keterampilan teknik gradasi, hal ini dilakukan untuk melihat sejauh mana peserta telah merasakan manfaat dengan pelatihan ini.

\section{Tahapan analisis data}

Tingkat keberhasilan atau evaluasi dari program kegiatan pengabdian diukur melalui kuesioner yang diberikan kepada peserta diawal sebelum melakukan pelatihan yang disebut (pre-test) dan juga di akhir pelatihan (post - test) dengan menggunakan skala Guttman. Yaitu skala yang menginginkan tipe jawaban tegas, seperti jawaban benar - salah, ya - tidak, pernah - tidak pernah, positif - negative, tinggi - rendah, baik - buruk, dan seterusnya. Pada skala Guttman, hanya ada dua interval, Yaitu Setuju dan tidak setuju. Skala Guttman dapat dibuat dalam bentuk pilihan ganda maupun daftar checklist. Untuk jawaban positif seperti benar, ya, tinggi, baik, dan semacamnya diberi skor 1; sedangkan untuk jawaban negative seperti salah, tidak, rendah, buruk, dan semacamnya diberi skor 0

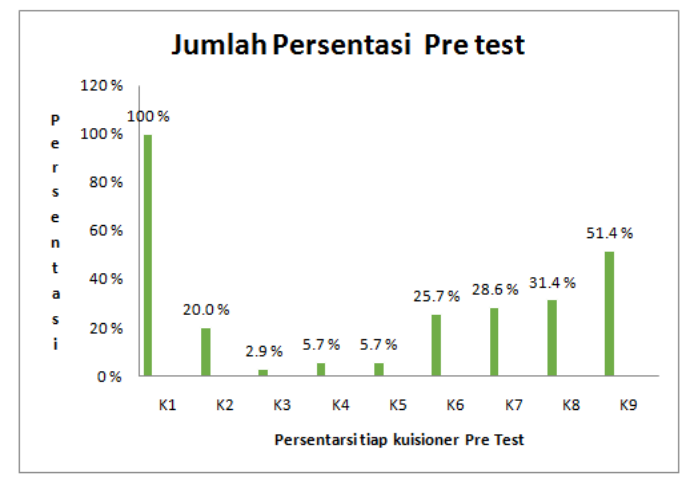

Gambar 5. Hasil Pengolahan Data Sebelum Dilakukan Pelatihan 


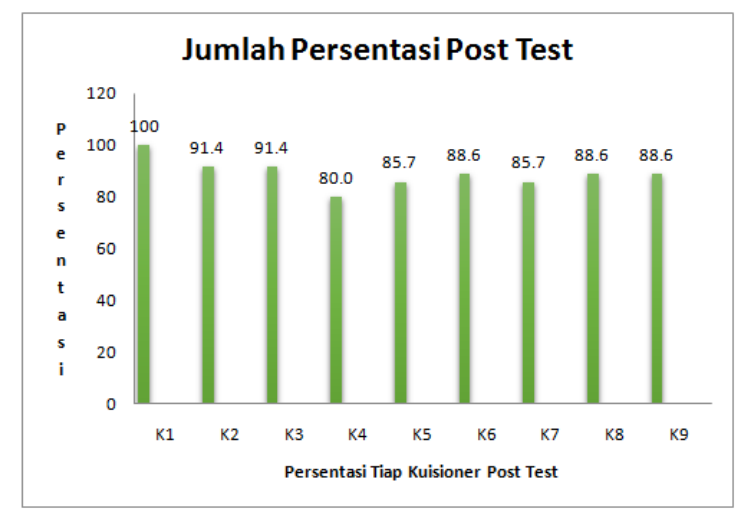

Gambar 6. Hasil Pengolahan Data Sesudah Dilakukan Pelatihan

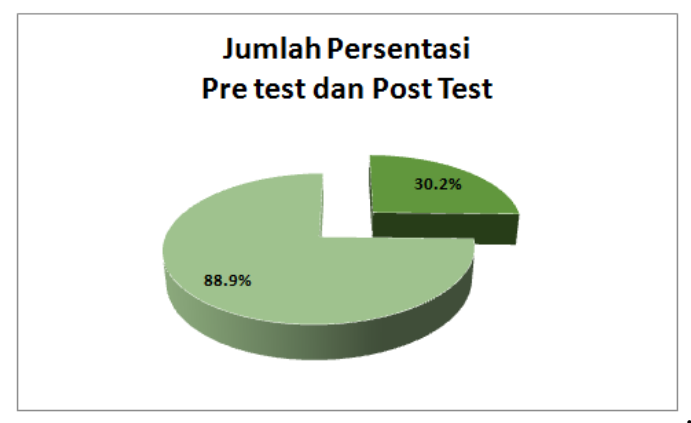

Gambar 7. Jumlah Presentasi Pre Test dan Post Test

Gambar grafik diatas menunjukkan bahwah $30.2 \%$ peserta sebelum mengikuti pelatihan menyatakan kemampuannya, sedangkan $88.9 \%$ peserta sesudah mengikuti pelatihan menyatakan kemampuannya, naik hingga $50 \%$.

\section{KESIMPULAN}

Dari seluruh rangkaian kegiatan dalam program pengabdian kepada masyarakat ini, dapat ditarik beberapa kesimpulan sebagai berikut:

a. Berdasarkan penyebaran kuisioner yang dilakukan sebelum melaksanakan pelatihan bahwa pengetahuan dan kemampuan peserta dalam membuat slide Power point yang efektif hanya 30.2 $\%$ dimana ini adalah pesertasi yang sangat kecil sedangkan setelah diberikan pelatihan pegetahuan peserta meningkat menjadi $88.9 \%$ dimana nilai persentasi tersebut mendekati ideal atau $100 \%$.

b. Berdasrkan hasil pretest dan posttest yang di isi oleh peserta, maka kita akan mendapatkan selisih peningkatan pengetahuan sebesar $58.7 \%$, dimana tingkat pengetahuan kemampuan peserta meningkat signifikan setelah dilakukannya pelatihan.

\section{DAFTAR PUSTAKA}

[1] Munawar. (2016). Pelatihan Penggunaan Power Point Untuk Membuat. Pelatihan Penggunaan Power Point Untuk Membuat Persentasi Menarik, 2, 6 